government and university scientists close together, but after WWII, despite early hopes that teaching and fundamental research could have priority over defence research, the government gained at the expense of the universities.

In 1931 there were 1,053 civil service scientists. By 1961 there were 15,474. Jones was critical of the trend and contrasted it with the United States, where nongovernmental laboratories had been fostered in the 1940s. Overenthusiastic claims for the Comet plane, thermonuclear fusion, the Einstein redshift in the Mössbauer effect and carbon fibres had not helped the reputation of the establishments. In wartime they flourished because of the spirit of collaboration. Not so in peacetime when the spirit was competitive.

Finally, how did scientific advice to the government change as a result of the war? Lord (alias Solly) Zuckerman sketched the transition from the advice, often informal, of the thirties, of Lindemann, Tizard, Blackett, Bernal, and so on, through the war when many scientists became planners with operational research and a few were involved in the determination of national policy, to the post war period with the greatly enhanced reputation of the scientist in government. Science advisers were brought in all over the place but their utility was restricted as they were rarely allowed to be more than technical assistants, kept out of the bigger issues of government. This trend culminated in the creation of a Chief Scientific Adviser in 1964, though if there were an issue on which he and trade union leaders had something to say, the trade unionists could be expected to carry more weight.

A fascinating meeting. Too bad the youngsters chose to stay in their laboratories. Those with scant regard for the history of science as a proper study (and there are many) would have been won over by this delightful occasion.

\title{
correspondence
}

\section{Nuclear simplicity}

SIR-The paramount command for nuclear power reactors is safety. The next most important requisite is the lowest possible cost of the electric power actually supplied to the grid.

Safety depends directly on simplicity and so does the cost of safety. An inherently simple plant can be made safe more easily and at a lesser cost. Simplicity also favours high availability and thus a lower unit cost of electrical power.

Simplicity is rare because new ideas are rare. The original safety containment concept was based on countering the hazard of brute force by brute strength until, quite late on, somebody hit on the idea of providing a condensational pool. The same is true of the coolant recirculation pumps: first external pumps with large connecting pipes, then external pumps with internal jets and small pipes, then axial internal pumps without any pipes. Pipes may fracture. In both cases the simpler and, with hindsight, very obvious concept resulted in lower costs and much greater safety.

I owe the concept of ponnery to my children who used to build edifices of chairs, saucepans, the cat's basket, vacuum cleaner and so on, up to the ceiling, one 'pon the other. Such an edifice is called a ponnery. I now classify nuclear reactors into 'naturals' and ponneries.

The naturals are simple and obvious. I know of only two: the boiling water reactor (BWR) and the gas-cooled fast breeder (GFB). The pressurised water reactor (PWR), the heavy water reactor (HWR) and the sodium-cooled fast breeder (SFB) are ponneries.

The BWR works on a direct cycle.
Disadvantage: active live steam. The main activity $\left({ }^{16} \mathrm{~N}\right.$, generated by activation of oxygen) is, however, so shortlived that only the head end of the turbine need be shielded. Advantages: inherent, very rapid reactivity control (voids ratio), so that load follow-up is automatic and power excursions are self-limiting. No primary/secondary heat exchangers, so, no unnecessary thermodynamic losses and no leaky tubes, therefore high availability.

The PWR is, by comparison, a ponnery. It has a complex primary cycle, huge primary/secondary heat exchangers (very expensive and very leakprone) and a low thermodynamic efficiency factor. High primary pressure (expensive), very modest live steam pressure (inefficient). From the nuclear point of view, sluggish reactivity control, hence the need for boron poisoning, hence a further sprouting of the ponnery to take the boron out again. It is inherent in a ponnery that the more you try to improve it the more profusely it sprouts.

The HWR introduces yet a third compartment, leaks from which must be controlled particularly carefully because heavy water is expensive. This is a ponnery within a ponnery. Its only advantage is the use of natural uranium. Once European enrichment facilities become available, this issue will be dead.

The obvious successor to the BWR is the fast breeder. But which one? The SFB is an obvious loser. It is of necessity a three-cycle system. Sodium is not a natural answer for transferring heat to water.

The natural winner seems to be the GFB, especially at high temperatures (process heat) and in combination with helium turbines (direct cycle, high effi- ciency, minimum waste heat dumping problems). The technological problems associated with high temperatures $\left(950^{\circ} \mathrm{C}\right.$ and more) are worth solving, in contrast to those of the SFB. In its prime, perhaps 10 years from now, the direct cycle GFB should prove even simpler than the BWR. Yours faithfully, T. O. LAzARIDES

Yeolmbridge House,

$\mathrm{Nr}$ Launceston,

Cornwall, UK

\section{Fishy correlations}

SIR,-In reference to the article What's in a Name? (Nature, 246, 385; 1973) and G. Curzon's letter (Nature, 247, $82 ; 1974)$ citing contributions to this field by brain research workers, the pioneering work of American ichthyologists must not go unmentioned ${ }^{1-4}$. Indeed the more than 300 ichthyological publications of Theodore N. Gill (1837. 1914) make him perhaps the most productive investigator in this esoteric science.

\section{Yours faithfully,} George Dale

Department of Ichthyology,

The American Museum of Natural History,

Central Park West at 79th Street, New York, New York 10024

'Fish, F. F., Furunculosis in wild trout; Copeia, 1937(1), 37 (1937).

${ }^{2}$ Fisher. G. C. Salt-water minnow in fresh water; Copeia, 1920(79), 18 (1920).

${ }^{3} A$ complete treatise on artificial fishbreeding ... . (edit. by Fry, W. H.), (New York, 1854).

${ }^{4}$ Pike, N., Notes on fishes of the ocean; Trans. R. Soc. Mauritius, n. s. 7, 27 (1873). 